\begin{tabular}{l} 
SCIENCE \& TECHNOLOGY \\
Journal homepage: http://www.pertanika.upm.edu.my/ \\
\hline PERTANIKA
\end{tabular}

\title{
Designing the Ergonomic Press and Molding Machine of Cassava Chips for Sustainable Development in SMEs
}

\author{
Silviana $^{1 *}$, Andy Hardianto ${ }^{1}$, Naif Fuhaid ${ }^{2}$ and Dadang Hermawan ${ }^{2}$ \\ ${ }^{1}$ Department of Industrial Engineering, Universitas Widyagama Malang, \\ Jl. Borobudur 35 Malang, 65125, Indonesia \\ ${ }^{2}$ Department of Mechanical Engineering, Universitas Widyagama Malang, \\ Jl. Borobudur 35 Malang, 65125, Indonesia
}

\begin{abstract}
The sustainability of the SMEs depends on how the SMEs could compete with their competitor. Utilizing technology is a way that can be used to survive in those competitions. Unfortunately, some of the SMEs in Indonesia could not afford to utilize the technology due to financial problems. Therefore, the aim of this research is to create an ergonomic working environment by utilizing the technology through the design of the press and molding machine. In its application, the concepts of Rapid Entire Body Assessment (REBA) and Rapid Upper Limb Assessment (RULA) were used to assess the working posture. The results of this assessment show that the working environment of this SME, especially in the pressing and molding process was not ergonomic and need to be improved. The given improvement is in the form of press and molding machine design and its prototype. The designing process was done using the concept of Quality Function Deployment (QFD). On the other side, to assess the level of success for the given design and machine, the REBA and RULA assessment was carried out. The results of the REBA and RULA assessment for the new machine showed that it could decrease the previous score of both REBA and RULA. The results of this research are expecting to increase the production capacity, minimizing

ARTICLE INFO

Article history:

Received: 17 January 2021

Accepted: 30 April 2021

Published: 31 July 2021 the occurrence of MSDs, and improving the quality of the chips. In the long-term, it will be able to increase the competitiveness of this SME.
\end{abstract}

DOI: https://doi.org/10.47836/pjst.29.3.24

E-mail addresses:

silviana.hakim@gmail.com (Silviana)

andyhardian@gmail.com (Andy Hardianto)

naif.uwg@gmail.com (Naif Fuhaid)

dadang@widyagama.ac.id (Dadang Hermawan)

* Corresponding author
Keywords: Ergonomic, posture, quality function deployment, rapid entire body assessment, rapid upper limb assessment 


\section{INTRODUCTION}

The use of technology has an important role both in big company and SMEs. With the existence technology, it can provide convenience in all aspects and even the users seem to be spoiled by the various conveniences that can be done. Besides, the use of technology could help the company to increase their competitiveness (Ahmedova, 2015). In contrary, many SMEs in Indonesia has a lot of difficulties such as lack of skills, funding, and technology which could decrease the ability to increase the competitiveness (Maksum et al., 2020). Whereas according to Ramayah et al. (2005) maintain the business competitiveness is the most important factor to keep the SMEs sustain in the long-term business survival.

The use of technology considered as an innovation in the business and machinery is categorized as a technology tools in the business operation (Rahman et al., 2016). The use of machinery in SMEs could shorten the production time, produce a product with a precise size, so that in the future it will be able to meet the market demand. Moreover, the use of machinery could minimize the occurrence of musculoskeletal disorders (MSDs) since most of the machine was made based on the certain health standard and pay attention to the user safety. MSDs are the injuries or pain in the joints of the body, ligaments, nerves, muscles, and structures that support the body or it can be called as a disorders that affect the movement of the body or the human skeletal muscle system (Revadi et al., 2019). Punchihewa (2010) stated that force (load), repetition, and posture such as prolonged static loads and forceful exertion, the extreme postures, and repetitive motion are the main factors that could causes MSDs.

This research was conducted in one of SMEs which produce cassava chips and located in Tulungagung, East Java, Indonesia. This SMEs produce chips using traditional tools, to be exact, they mold the chips by the fork and press it. Those action has been done in repetitive. In the long-term, this matter could lead to the musculoskeletal disorders (MSDs). Besides, since this process was done manually, it can affect the size of the chips. The results of observations in the field showed that the chips have a different diameter and thickness. Therefore, an effort is needed to deal with these various problems. The objective of this research is to design the ergonomic press and molding machine using the concept of ergonomic and Quality Function Deployment (QFD). In the future, this machine design is expected to be able to increase the production capacity, produce chips with more precise size, and be able to reduce the possibility of MSDs due to repetitive motion. Furthermore, in the long-term this machine is expected to be able to increase the competitiveness of this SMEs.

\section{LITERATURE REVIEW}

Biomechanics studies the strength, endurance, speed, accuracy, and limitations of humans in carrying out the activities. This factor is closely related to material handling activities, 
such as manual lifting and moving, and other jobs that involve a lot of body muscles. Besides, work posture is a determining point in analyzing the effectiveness of a job. If the work posture that has been carried out by the operator is good and ergonomic, then it can be ascertained that the results obtained by the operator will be good, but if the operator's work posture is wrong or not ergonomic then the operator will be easily tired, and it may cause the MSDs. If the operator is easily tired, the results of the work will also decrease and are not as expected (Akshinta \& Susanty, 2017).

Rapid Upper Limb Assessment (RULA) is the survey method in ergonomic which is used as an investigation tools in determine the MSDs. It is the simplest, easiest to understand, and quick to complete. This method used to assess the biomechanical and the work postures based on the body position while doing the activity. The assessment of RULA can be done with the help of RULA worksheet that has been proposed. RULA assessment is mainly focus on the upper body, which consist of neck, trunk, upper arm, and lower arm. Besides, this method also assess the function of muscle and the loads (Ijaz et al., 2020). RULA is a method to analyzing the ergonomics of a work posture with the use of the upper body. RULA analysis is carried out if there is a report about the complaints in the upper body caused by unergonomic postures. The RULA method is easy to use because it does not require any special equipment in its implementation. Some of the factors analyzed by the RULA method are work position in a static state, workload, work period, and also muscle energy used (Tiogana \& Hartono, 2020).

Meanwhile, Rapid Entire Body Assessment (REBA) is the most detailed assessment since it assesses all the movement of the entire body while doing the activity. This method was developed to evaluate the potential work related to the MSDs. Besides, REBA was designed to make it easy to understand and there is no need for the high skill or expensive equipment. The REBA worksheet and a stationary was the things that needed when conducting this assessment (Tiogana \& Hartono, 2020). The aim of this method is to divide the body to a different portion then separately assess it based on its angles. As well as the RULA, the REBA assessment was conducted using the help of REBA worksheet. In this assessment, the scores were obtained from the body postures alignment, the weight on muscles and the coupling scores. The final scores of REBA assessment is the summation of values from both groups. According to Ijaz et al. (2020) the loading of biomechanical and postural has always been successfully assessed using this simple worksheet. The scores were obtained from a different body part such as trunk, neck, and legs in the section A, whereas the section $\mathrm{B}$ consist of the assessment of the upper and lower arm, wrist, and wrist twist. In the section $\mathrm{C}$, the summation of both score in section A and B was conducted. The REBA assessment could highlight and determine the level of urgency.

The use of RULA and REBA assessment made the analysis of work posture are easy and reliable. Moreover, Kee et al. (2020) stated in their research that RULA is the best 
technique that could be used for assessing the working posture. On the other hand, some of the research also highlighted the use of this method if it will be used alone or combined it with other method. Punchihewa (2010) stated that conducting the REBA technique without being combined with other method will be failed to give the best solution to minimize the MSDs. It will be better if the designing process was included in those assessment. Therefore, in this research the designing process using QFD will be included.

Quality Function Deployment (QFD) is the deployment tools which is widely used in the total quality management (TQM). QFD is a process to translating the requirements of customer into the technical requirements of a product. This process started with capturing the voice of customer into the product and fed into the product through the technical definitions of each customer demand in the effective way (Shil et al., 2010). In the product planning, a trade-off will be reached if the customer requirements and the technical adaptability are be depicted through the house of quality (HOQ). QFD approach is based on the deploying consumer expectations (What) in term of design and productionparameters (How). The correlations between what and how will be explained in the HOQ matrix. This matrix allows the integrations between the related elements to analyzing the product competition and to identifying the synergies and the contra-dictions between different characteristic of the product. Thus, this matrix offers the advantages for the user, the designer, and also for the decision maker of the product development (Marsot, 2005).

\section{RESEARCH METHODOLOGY}

This study was conducted at the Cassava Chips-SMEs in Tulungagung, East Java, Indonesia. This research was divided into three main stages, first is the observation in the field, followed by an assessment of work posture using the REBA RULA method, and ended by the designing process. The results of the observation in the field showed that this SME was facing problems such as the use of traditional equipment that causes the chips has a different size, and the work environment which is not ergonomic. Therefore, the objectives of this research are to designing the press and molding machine that can be used to minimize those problems. Figure 1 shows the stages of this research.

This research began with the observation stages, this stage has been done to find out the problems that are currently faced by this SME. The next step is to conduct the literature review. This step is done to find out the appropriate method that can be used to solve those problems. After finding out the appropriate method, the next stage is the assessment. This

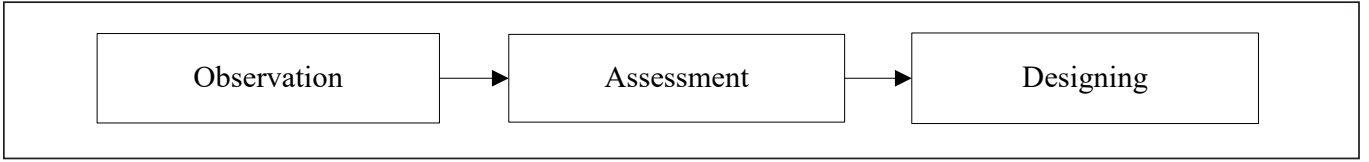

Figure 1. The stages of the research 
assessment is conducted to assess the current condition and to double-check the working posture during the production process. The concepts of REBA and RULA were used to conducting that assessment. The results of the assessment will be used as a reference in designing the machine. The last stages, the designing stages was conducted using the concept of QFD. The designing process was done according to the voice of the customer and prioritizing scale in the HOQ matrix. The designing process also includes the prototyping of the machine.

\section{RESULTS AND DISCUSSION}

The results of field observations indicate that this SME is still using traditional equipment in its production process. Even though it has a large market demand, in practice the carried-out production capacity is still insufficient. This is due to inadequate production equipment. This SME produces cassava chips as its main product. The process of making these chips begins with peeling the cassava skin, which is the main ingredient, then the cassava will be milled and stored in the refrigerator for two days. The cassava dough that has been stored in the refrigerator for 2 days will be mixed with various spices, stirred, and molded. The molding process was done in the standing position and was traditionally undertaken using the help of a tray and fork. A tablespoon of the dough will be pressed into the tray and will be molded using a fork. The molding process is carried out repetitively so that in the long-term it may cause MSDs. In addition, due to the manual use of tools, the results of the molding also have different thicknesses and diameters. So, it can be said that this traditional pressing and molding process is able to have a negative impact on the sustainability of this SME. Therefore, it is necessary to design the ergonomic press machine so that the negatives impact can be reduced.

The next step of producing the cassava chips is steaming. The cassava dough that has been molded will be steamed for approximately 4-5 minutes. After being steamed, the dough will be dry in the sun for about 2-3 days. The last step is the packaging process, this SME produced 2 kinds of chips package that is the raw and the cooked one. All those variants will be packed in 2 ounces or $1 \mathrm{~kg}$ packaging. In this research, the focus will be on the pressing and molding process since it has a problem that needs to be improved. The improvement begins with conducting the assessment using REBA \& RULA concepts. The objective of this assessment is to check or assess the current work posture in the pressing and molding process. Figure 2 shows the results of the REBA assessment.

Figure 2 explain the step of conducting REBA assessment. The results of the assessment showed that the REBA score is 5 which means that the work posture in pressing and molding process are in the medium risk and further investigation and change are needed. This matter will be used as a reference to design the machine. Furthermore, the RULA assessment was also carried out. Figure 3 shows the step of RULA assessment. 


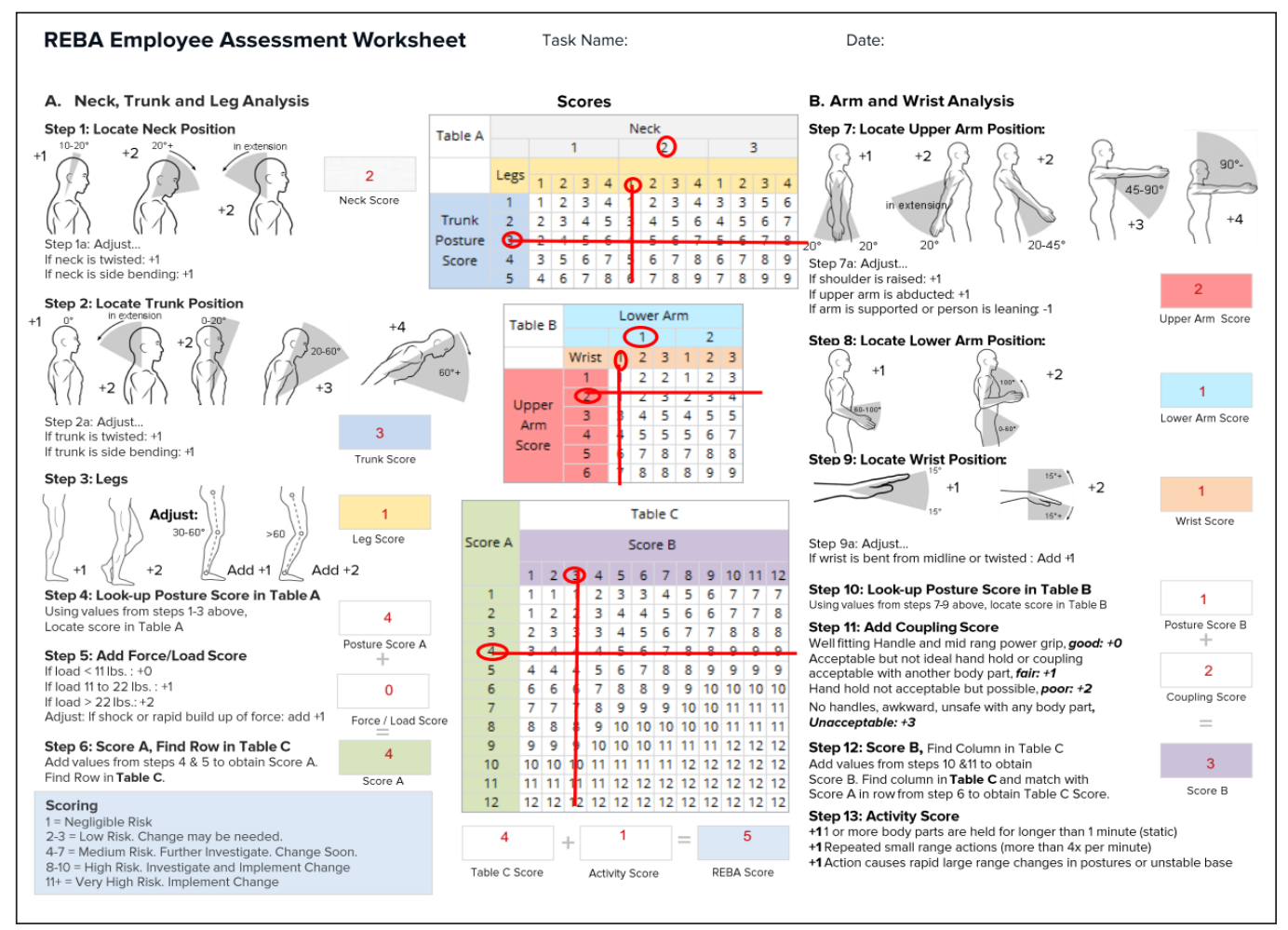

Figure 2. The results of REBA assessment

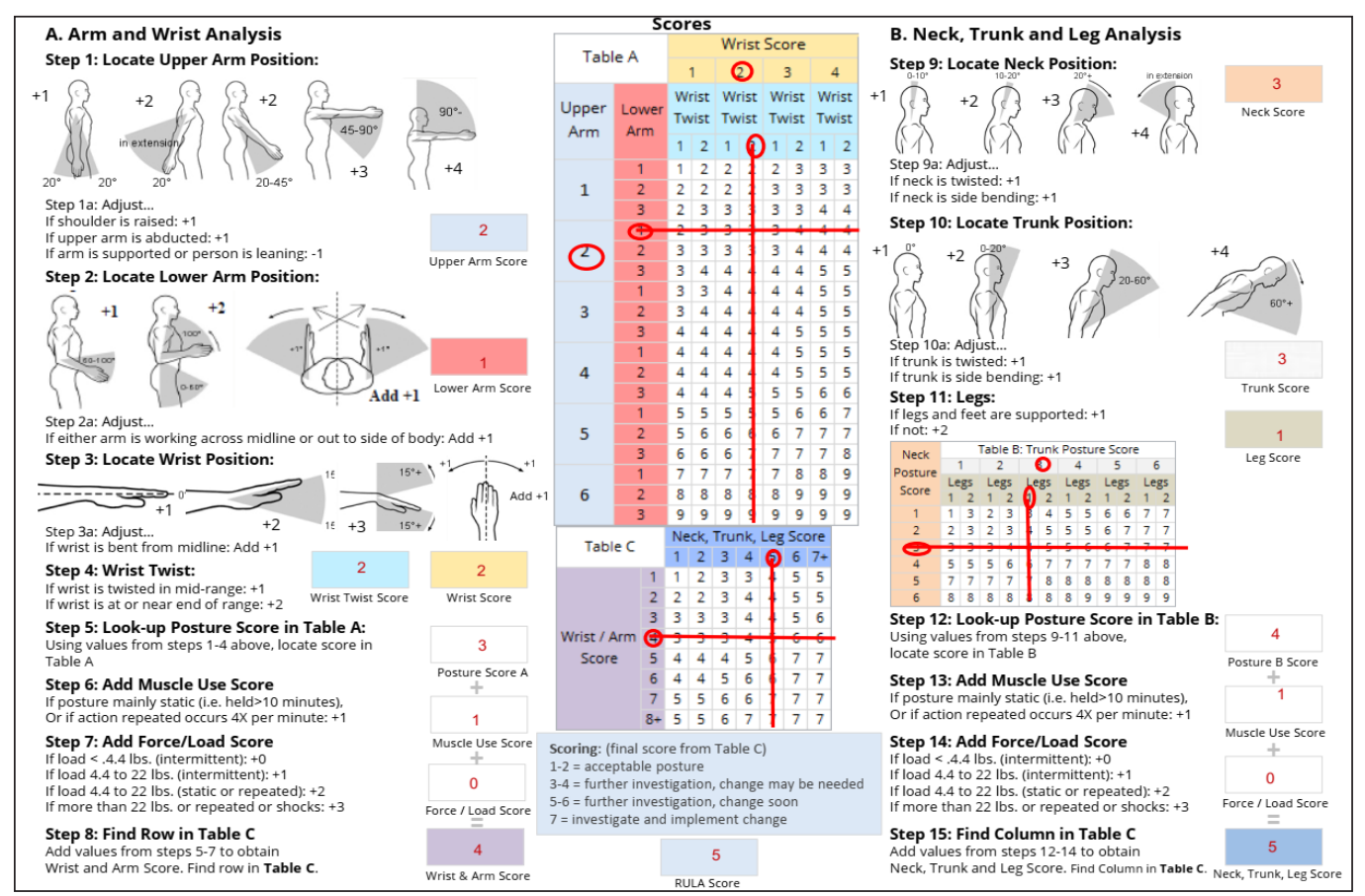

Figure 3. The results of RULA assessment 
The results of the assessment showed that the RULA score is 5 which means further investigation and change are needed soon. The risk assessment that has been done using REBA and RULA concepts needs to be combined with other methods to providing the appropriate solutions. According to Punchihewa (2010), some researchers used the REBA technique to assess the risk of MSDs but it is not combined with other methods. As a result, those tools failed to provide the best solution to minimize the MSDs. This method might be useful if the designed process is integrated to help the designers to communicate about the requirements. QFD is the potential method that could improving this drawback. QFD is a helpful method that could communicating the requirements for the design with other information of the product design. Besides, QFD also known as the powerful tool in fulfills the customer satisfaction by translating the voice of customer in the designing or product development (Shil et al., 2010). On the other sides, Hashim and Dawal (2012) stated that QFD can be used as a tools to help the prioritizing process of the design requirement based on their important values so that the customer expectations can be fulfilled. Considering the advantages of QFD, therefore the designing process of press and molding machine will be conducted using QFD.

The first step before designing the HOQ matrix is to propose the list of the voice of customers. This step was conducted through the interview with the employee of this SME. The results of the interview will be used as the statement in the questionnaire. A Likert scale from 1 to 5 was used to give the answer. The questionnaires will be distributed to all the employees and the owner, which is a total 30 number of people. The results of the questionnaire will be evaluated using reliability tests and validity tests. The aim of this test is to determine the validity or suitability of the questionnaire which is used by researchers to obtain data from respondents. The reliability and validity tests were conducted using the help of SPSS software. Figure 4 shows the results of the reliability test.

Figure 4 shows that the data obtained from the respondents are reliable since the Cronbach's Alpha is 0.426 which is greater than the score of the $\mathrm{R}$ table, 0.361 . Therefore, it can be concluded that the data was reliable and consistent. Meanwhile, to figure out the validity of the data, a validity test was conducted. Figure 5 shows the results of the validity test using SPSS.

The results of validity tests using SPSS shows that the value of Pearson Correlation to all the variable has a greater value than the $\mathrm{R}$ table which is 0.361 . Therefore, it concluded that the used data was valid. Furthermore, all the gathered voice of customers will be used and placed in the left-hand column of HOQ matrix. Meanwhile, the technical requirements will be identified by the QFD team or in this research is known as the

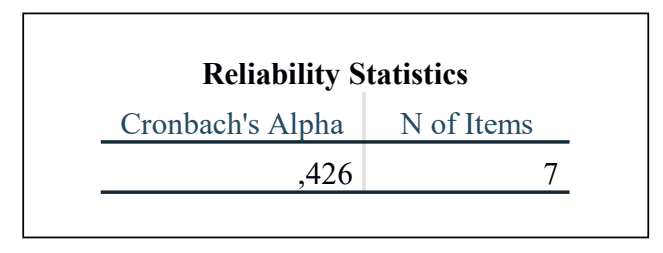

Figure 4. Results of Reliability Test 


\begin{tabular}{|c|c|c|c|c|c|c|c|c|c|}
\hline & & V1 & $\mathrm{V} 2$ & $\mathrm{~V} 3$ & V4 & V5 & V6 & V7 & Total \\
\hline \multirow[t]{3}{*}{ V1 } & Pearson Correlation & 1 & -0.027 & 0.074 & 0.137 & 0.091 & -0.087 & 0.201 & $0.428^{*}$ \\
\hline & Sig. (2-tailed) & & 0.889 & 0.697 & 0.472 & 0.631 & 0.647 & 0.286 & 0.018 \\
\hline & $\mathrm{N}$ & 30 & 30 & 30 & 30 & 30 & 30 & 30 & 30 \\
\hline \multirow[t]{3}{*}{ V2 } & Pearson Correlation & -0.027 & 1 & -0.039 & $0.398^{*}$ & 0.014 & 0.216 & 0.000 & $0.475^{* *}$ \\
\hline & Sig. (2-tailed) & 0.889 & & 0.838 & 0.029 & 0.943 & 0.251 & 1.000 & 0.008 \\
\hline & $\mathrm{N}$ & 30 & 30 & 30 & 30 & 30 & 30 & 30 & 30 \\
\hline \multirow[t]{3}{*}{ V3 } & Pearson Correlation & 0.074 & -0.039 & 1 & 0.339 & 0.000 & -0.183 & $0.473^{* *}$ & $0.465^{* *}$ \\
\hline & Sig. (2-tailed) & 0.697 & 0.838 & & 0.067 & 1.000 & 0.334 & 0.008 & 0.010 \\
\hline & $\mathrm{N}$ & 30 & 30 & 30 & 30 & 30 & 30 & 30 & 30 \\
\hline \multirow[t]{3}{*}{ V4 } & Pearson Correlation & 0.137 & $0.398^{*}$ & 0.339 & 1 & 0.040 & 0.120 & 0.136 & $0.652^{* *}$ \\
\hline & Sig. (2-tailed) & 0.472 & 0.029 & 0.067 & & 0.835 & 0.527 & 0.472 & 0.000 \\
\hline & $\mathrm{N}$ & 30 & 30 & 30 & 30 & 30 & 30 & 30 & 30 \\
\hline \multirow[t]{3}{*}{ V5 } & Pearson Correlation & 0.091 & 0.014 & 0.000 & 0.040 & 1 & 0.013 & 0.069 & $0.373^{*}$ \\
\hline & Sig. (2-tailed) & 0.631 & 0.943 & 1.000 & 0.835 & & 0.946 & 0.715 & 0.042 \\
\hline & $\mathrm{N}$ & 30 & 30 & 30 & 30 & 30 & 30 & 30 & 30 \\
\hline \multirow[t]{3}{*}{ V6 } & Pearson Correlation & -0.087 & 0.216 & -0.183 & 0.120 & 0.013 & 1 & 0.066 & $0.367^{*}$ \\
\hline & Sig. (2-tailed) & 0.647 & 0.251 & 0.334 & 0.527 & 0.946 & & 0.728 & 0.046 \\
\hline & $\mathrm{N}$ & 30 & 30 & 30 & 30 & 30 & 30 & 30 & 30 \\
\hline \multirow[t]{3}{*}{ V7 } & Pearson Correlation & 0.201 & 0.000 & $0.473^{* *}$ & 0.136 & 0.069 & 0.066 & 1 & $0.569^{* *}$ \\
\hline & Sig. (2-tailed) & 0.286 & 1.000 & 0.008 & 0.472 & 0.715 & 0.728 & & 0.001 \\
\hline & $\mathrm{N}$ & 30 & 30 & 30 & 30 & 30 & 30 & 30 & 30 \\
\hline \multirow[t]{3}{*}{ Total } & Pearson Correlation & $0.428^{*}$ & $0.475^{* *}$ & $0.465^{* *}$ & $0.652^{* *}$ & $0.373^{*}$ & $0.367^{*}$ & $0.569^{* *}$ & 1 \\
\hline & Sig. (2-tailed) & 0.018 & 0.008 & 0.010 & 0.000 & 0.042 & 0.046 & 0.001 & \\
\hline & $\mathrm{N}$ & 30 & 30 & 30 & 30 & 30 & 30 & 30 & 30 \\
\hline
\end{tabular}

Figure 5. The Results of Validity Test using SPSS

*. Correlation is significant at the 0.05 level (2-tailed).

**. Correlation is significant at the 0.01 level (2-tailed).

researchers. Besides, the relationship between the customer requirements and technical requirements were also generated by the QFD team. In the right-hand column, competitive analysis was performed with five competitors. The relations between the technical requirements and the degree of difficulty were established based on the knowledge of the experts, and also the recommendations of the consultants (Erdil \& Arani, 2019). Figure 6 shows the proposed HOQ that has been done in this research.

The results of the HOQ matrix show that the voice of customer which has the highest importance level, respectively are the conveniences while using the machine, user friendly, has an ergonomic design, and can increasing the production capacity. Therefore, the 


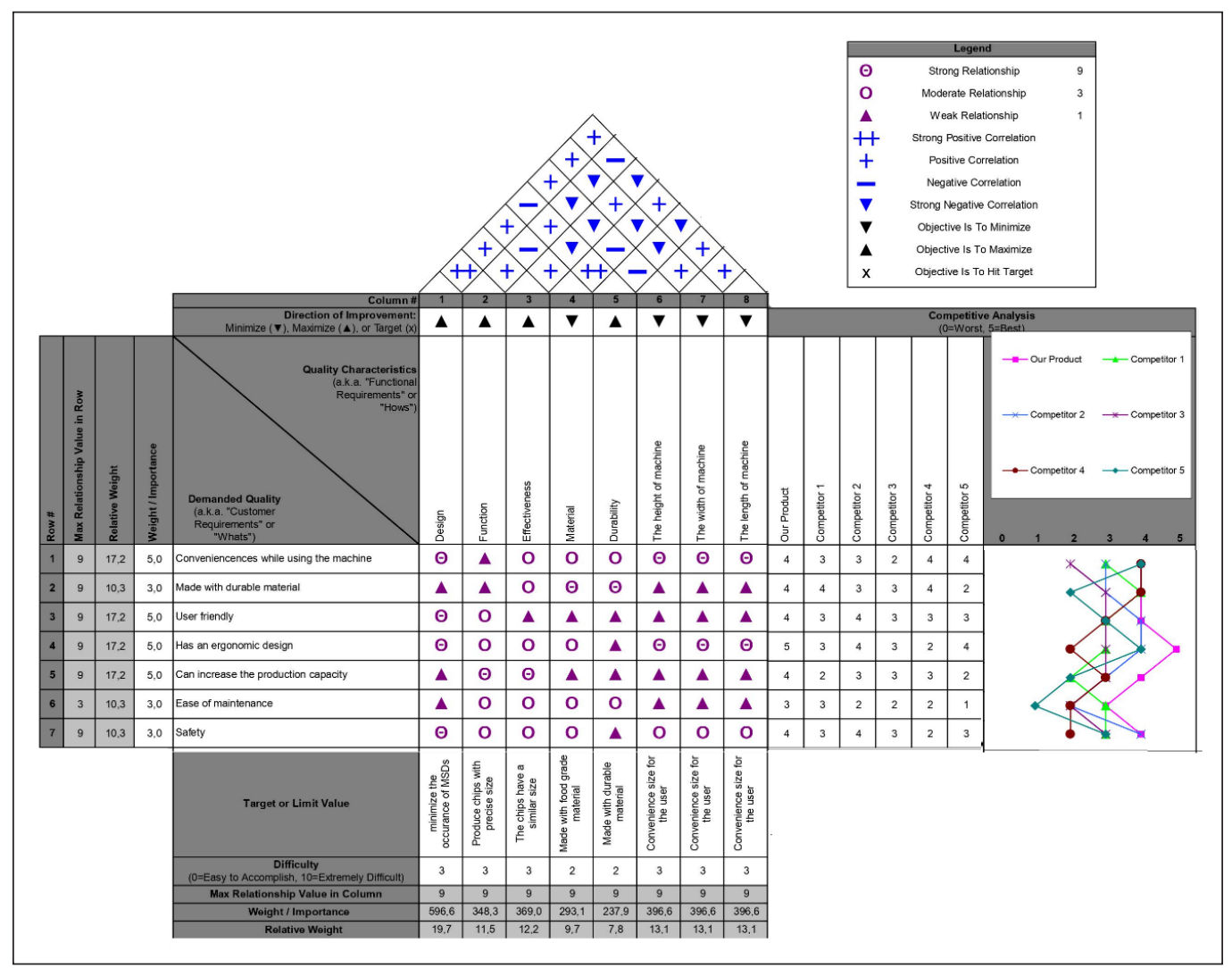

Figure 6. The HOQ Matrix
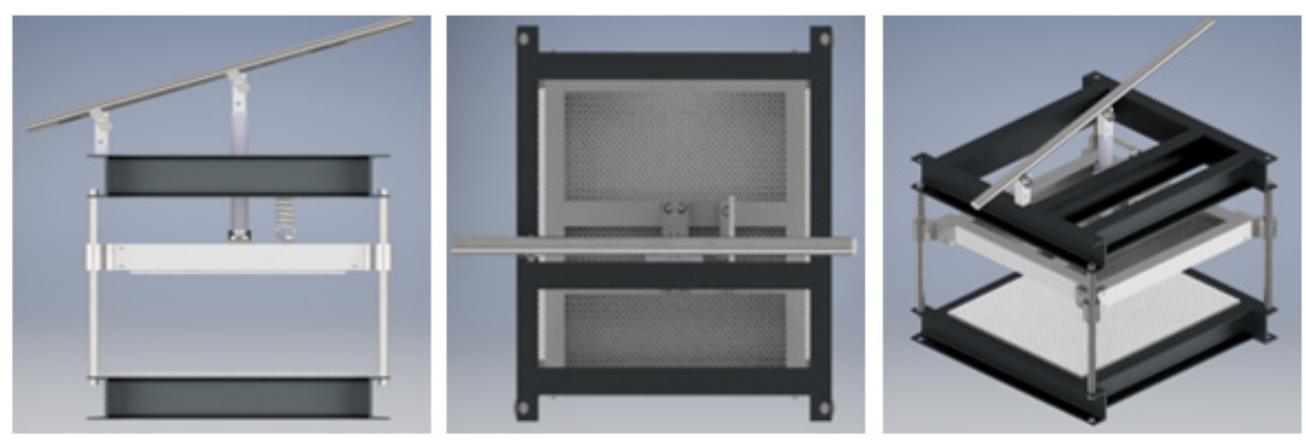

Figure 7. The design of pressing and molding machine

given design of press and molding machine will be referring to those attributes so that the customer satisfaction can be fulfilled. Figure 7 shows the proposed design of pressing and molding machine.

According to the voice of a customers, the provided machine design is ergonomically designed in such a way as to provide conveniences to its users. Hence, the size of the 


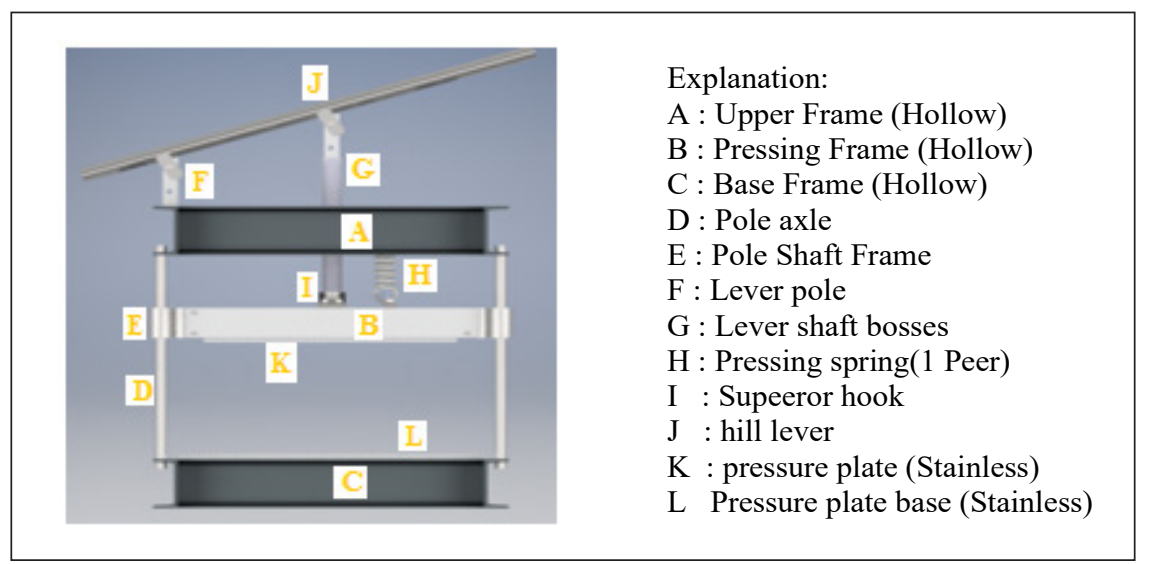

Figure 8. The part of the machine

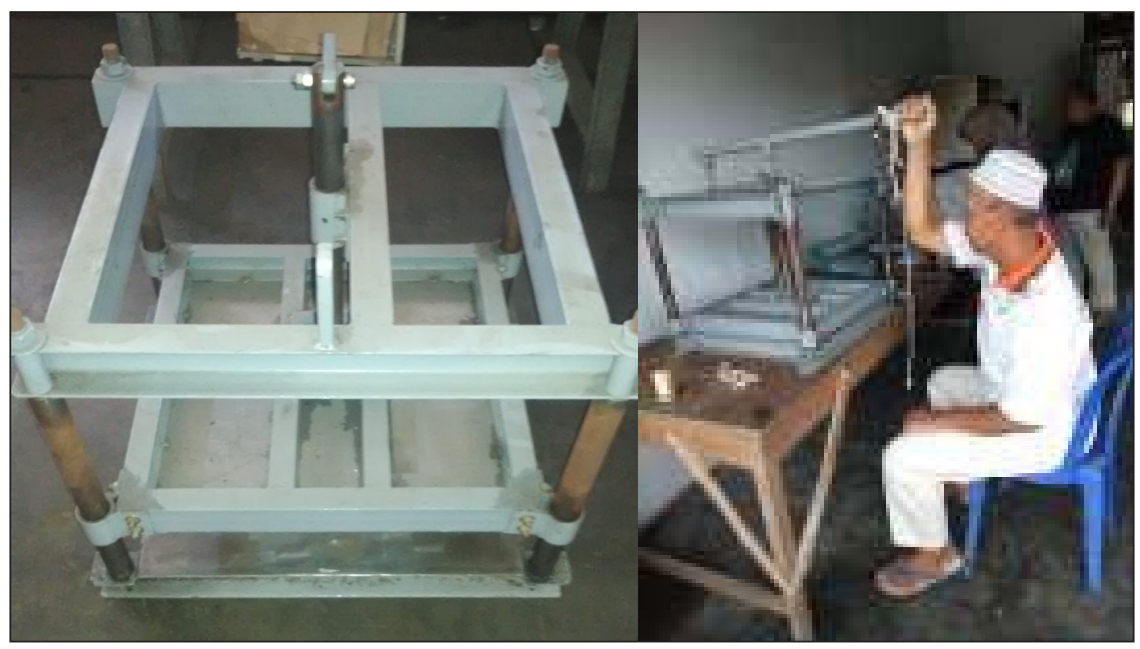

Figure 9. The prototype of pressing machine

machine is being concerned so that the fatigue could be reduced. Besides, to avoid fatigue when doing the pressing and molding process, the machine design will be placed on the table so that the body position while doing the pressing and molding is in a sitting position. Figure 8 shows that it has a user-friendly design so that it will be easier to use, even the maintenance process is easy to do. This design is expected to increase the number of production capacity of this SME. Figure 9 shows the prototype of this design.

Figure 9 shows that the machine was executed by hand but in an ergonomic manner. Besides, this machine was made for the sitting position. The used material consists of iron and stainless steel. As stated in the previous section, this SME still utilizes the traditional equipment to do the pressing and molding process, and which done manually so that it will take a long time to press and molding the chips and resulting in the differences in both 


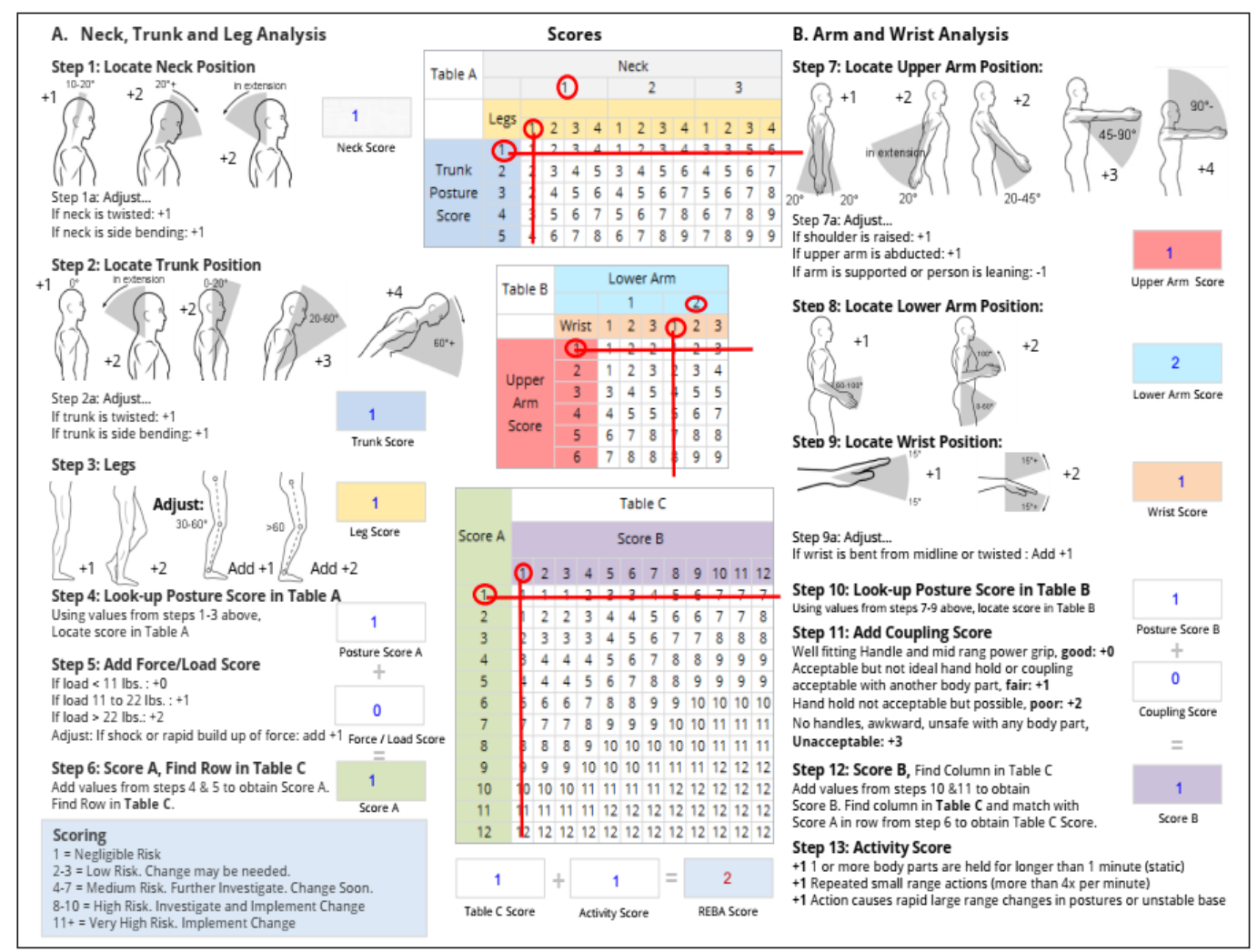

Figure 10. The Results of REBA assessment

the thickness and the diameter. Some of the advantages offered by this machine are the molding time is 0.5 minutes per tray which is 16 chips in a tray, the used of this machine could minimize the occurrence of fatigue, has a strong and stable construction, and utilizes the food grade material. On the other side, to prove that the given design has been able to reduce the problems faced by this SME, the assessment using REBA and RULA was conducted once more. Figure 10 shows the results of the REBA assessment meanwhile Figure 11 shows the results of the RULA assessment.

The results of the REBA assessment show that the score of REBA was 2 which is means that the new machine has a low risk, and the change may be needed. When compared with the previous assessment, the score has been decreased from 5 to 2. Besides, the results of the RULA assessment also showed the significant results. Figure 11 shows the calculation of RULA assessment.

The results of the RULA assessment for the given machine also gave positive feedback. Figure 11 shows that the score of the RULA assessment is 2 which means acceptable posture. Compared with the previous assessment, the new machine is succeeding to decrease the score from 5 to 2 . 


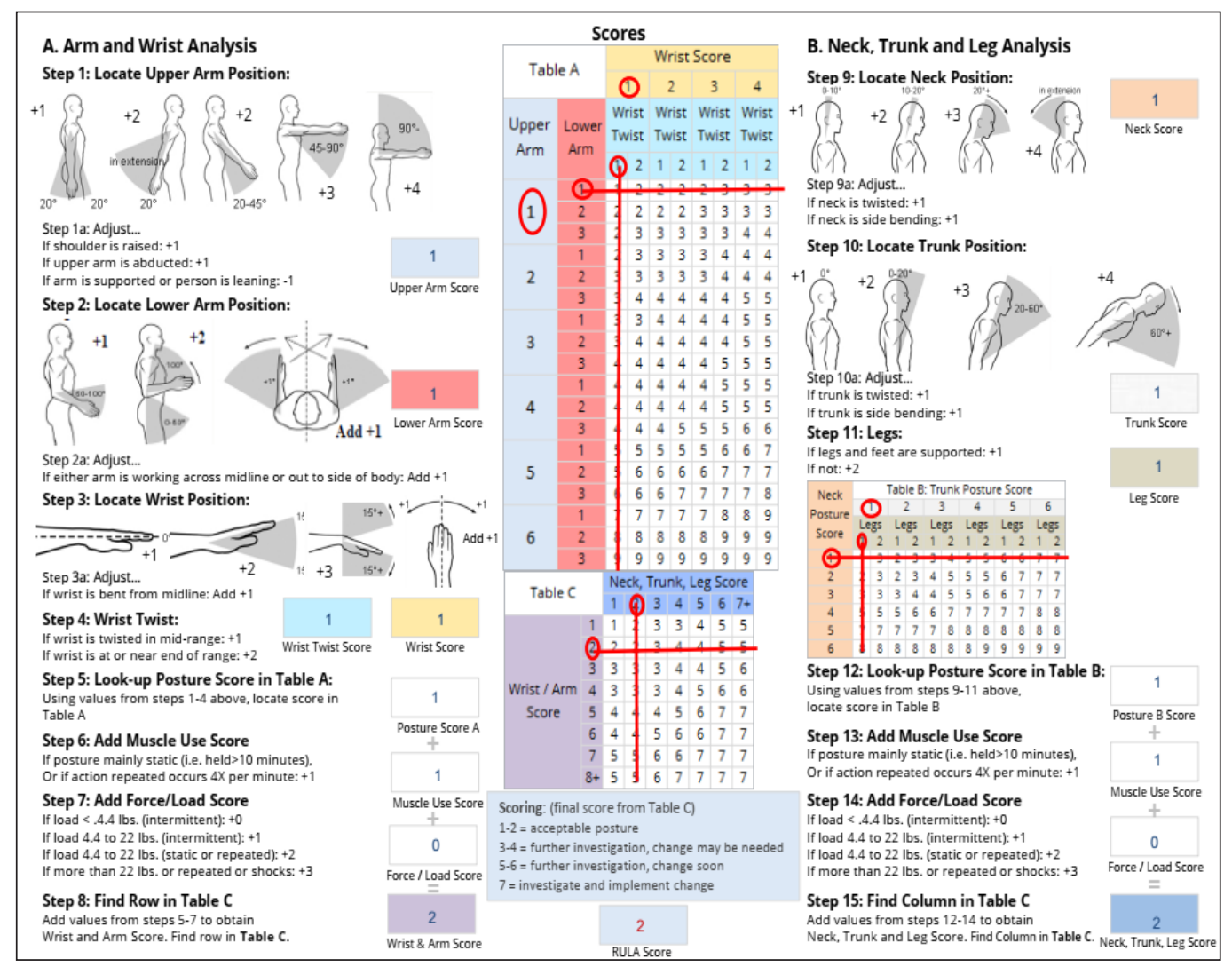

Figure 11. The Results of RULA assessment

\section{CONCLUSION}

The results of the posture assessment using REBA RULA show that the pressing and molding processes need to be improved. The improvement process is carried out by designing a pressing and molding machine. The results on the HOQ matrix show that the conveniences of the user, has an ergonomic design, user friendly, and could increase the production capacity are the voice of customers with the largest priority scale. Therefore, the given design will refer to these requirements. This research is not only designing the machine but also create the machine prototype which also refers to the customer requirements. The designed machine is capable to produce 16 chips in 0.5 minutes and the production results have a high degree of precision. Besides, to prove that the given recommendations gave the positives impacts, the REBA and RULA assessment of the new machine was conducted. The results of the REBA and RULA assessment show that the use of a new machine could decrease the score from the previous assessment. Therefore, it can be concluded that the use of the new machine is able to solve the problems faced by this SME. For future research, a cost analysis might be needed. 


\section{ACKNOWLEDGEMENT}

This project is funded by The Ministry of Research, Technology and Higher EducationDirectorate General of Higher Education, Indonesia. We are so thankful for the financial support from Ministry of Research, Technology and Higher Education- Directorate General of Higher Education.

\section{REFERENCES}

Ahmedova, S. (2015). Factors for Increasing the Competitiveness of Small and Medium- Sized Enterprises (SMEs) in Bulgaria. Procedia - Social and Behavioral Sciences, 195(February), 1104-1112. https://doi. org/10.1016/j.sbspro.2015.06.155

Akshinta, P. Y., \& Susanty, A. (2017). Analisis RULA (rapid upper limb assessment ) dalam menentukan perbaikan postur pekerja las listrik resiko musculoskeletal disorders [Analysis RULA (rapid upper limb assessment) in determining improvement posture workers electrical welding in a welding shop electricity to reduce the risk musculoskeletal disorders]. Industrial Engineering Online Journal, 6(1), 1-10.

Erdil, N. O., \& Arani, O. M. (2019). Quality function deployment: More than a design tool. International Journal of Quality and Service Sciences, 11(2), 142-166. https://doi.org/10.1108/IJQSS-02-2018-0008

Hashim, A. M., \& Dawal, S. Z. M. (2012). Kano model and QFD integration approach for ergonomic design improvement. Procedia - Social and Behavioral Sciences, 57(October), 22-32. https://doi.org/10.1016/j. sbspro.2012.09.1153

Ijaz, M., Ahmad, S. R., Akram, M., Khan, W. U., Yasin, N. A., \& Nadeem, F. A. (2020). Quantitative and qualitative assessment of musculoskeletal disorders and socioeconomic issues of workers of brick industry in Pakistan. International Journal of Industrial Ergonomics, 76(August 2019), Article 102933. https:// doi.org/10.1016/j.ergon.2020.102933

Kee, D., Na, S., \& Chung, M. K. (2020). Comparison of the ovako working posture analysis system, rapid upper limb assessment, and rapid entire body assessment based on the maximum holding times. International Journal of Industrial Ergonomics, 77(December 2019), Article 102943. https://doi.org/10.1016/j. ergon.2020.102943

Maksum, I. R., Rahayu, A. Y. S., \& Kusumawardhani, D. (2020). A social enterprise approach to empowering micro, small and medium enterprises (SMEs) in Indonesia. Journal of Open Innovation: Technology, Market, and Complexity, 6(3), Article 50. https://doi.org/10.3390/joitmc6030050

Marsot, J. (2005). QFD: A methodological tool for integration of ergonomics at the design stage. Applied Ergonomics, 36(2), 185-192. https://doi.org/10.1016/j.apergo.2004.10.005

Punchihewa, H. K. G. (2010). The potential of quality function deployment (QFD) in reducing work-related musculoskeletal disorders (Doctoral dissertation). Loughborough University, England. Retrieved February 23, 2021, from https://repository.lboro.ac.uk/articles/thesis/The_potential_of_Quality_Function_ Deployment_QFD_in_reducing_work-related_musculoskeletal_disorders/9356639

Rahman, N. A., Yaacob, Z., \& Radzi, R. M. (2016). An overview of technological innovation on SME survival: A conceptual paper. Procedia - Social and Behavioral Sciences, 224(August 2015), 508-515. https://doi. org/10.1016/j.sbspro.2016.05.427 
Ramayah, T., Lim, Y. C., \& Mohamed, S. (2005). SME e-readiness in Malaysia: Implications for planning and implementation. Sasin Journal of Management, 11(1), 103-120.

Revadi, C. E., Gunawan, C. S., \& Rakasiwi, G. J. (2019). Prevalensi dan faktor-faktor penyebab musculoskeletal disorders pada operator gudang industri ban PT X Tangerang Indonesia [Prevalence and factors causing musculoskeletal disorders at the operator of tire industry warehouse PT X Tangerang, Indonesia]. Jurnal Ergonomi Indonesia (The Indonesian Journal of Ergonomic), 5(1), 10-15. https://doi.org/10.24843/ jei.2019.v05.i01.p02

Shil, N. C., Ali, M. A., \& Paiker, N. R. (2010). Robust customer satisfaction model using QFD. International Journal of Productivity and Quality Management, 6(1), 112-136. https://doi.org/10.1504/ IJPQM.2010.033887

Tiogana, V., \& Hartono, N. (2020). Analisis Postur Kerja dengan Menggunakan REBA dan RULA di PT X [Worker posture analysis using REBA and RULA at PT X.]. Journal of Integrated System, 3(1), 9-25. https://doi.org/10.28932/jis.v3i1.2463 